\title{
CONTRIBUIÇÕES DA ANTROPOLOGIA PARA O CAMPO DA EDUCAÇÃO EM SAÚDE NO BRASIL
}

CONTRIBUTIONS OF ANTHROPOLOGY TO THE FIELD OF HEALTH EDUCATION IN BRAZIL

CONTRIBUCIONES DE LA ANTROPOLOGÍA EN EL CAMPO DE LA EDUCACIÓN PARA LA SALUD

EN BRASIL

João Vinícius dos Santos Dias ${ }^{1}$

Jaqueline Ferreira $^{2}$

Resumo O objetivo deste artigo é resgatar aspectos relativos à constituição da educação em saúde como campo científico. Mostra as principais transformações ocorridas desde as concepções autoritárias e etnocêntricas em relação a seus grupos-alvo até as atuais propostas de educação popular de valorização do saber popular, inspiradas no pensamento de Paulo Freire. Defende que a postura do antropólogo em campo, ao buscar valorizar o saber do Outro como tão legítimo quanto o acadêmico, pode auxiliar os profissionais de saúde na prática de uma educação em saúde dialógica, para os grupos aos quais se destina.

Palavras-chave educação em saúde; antropologia; saúde coletiva; etnografia.
Abstract The purpose of this article is to rescue aspects related to the construction of health education as a scientific field. It presents the main changes that have occurred since the early authoritarian and ethnocentric views concerning its target groups to the current proposals for popular education to value popular knowledge, inspired by the thought of Paulo Freire. It argues that the anthropologist's stance in the field, seeking to value the knowledge of the Other as just as legitimate as the academic one, can help health professionals practice dialogic health education for the groups to which it is intended.

Keywords Health education; anthropology; public health; ethnography. 
Medidas de educação em saúde têm sido uma inquietação de profissionais de saúde há vários séculos; no entanto, as diferentes propostas educativas vêm se organizando de diferentes formas, de acordo com distintos contextos sócio-históricos: vão das posturas coercitivas e autoritárias da polícia médica alemã, no século XVIII, até as propostas atuais, com foco em uma relação pautada no diálogo horizontalizado entre profissionais de saúde e população. A educação em saúde tem sido atravessada por diferentes processos, com inserção de diferentes disciplinas de categorias profissionais, com o objetivo de contribuir para a proposta de promoção à saúde.

Este artigo propõe-se a recuperar a maneira como esse processo se constituiu no Brasil. Para tanto, recorre a um breve resgate histórico do percurso da educação em saúde brasileira e de sua consolidação como campo científico. Tendo em vista a relação de forças e dos processos que regulam as sociedades modernas, ou seja, a mediação entre os agentes sociais e a sociedade, o conceito de campo de Bourdieu (1976) nos parece pertinente a ser aplicado na educação em saúde no Brasil. Segundo o autor,

O campo científico, enquanto sistema de relações objetivas entre posições adquiridas (em lutas anteriores), é o lugar, o espaço de jogo de uma luta concorrencial. O que está em jogo especificamente nesta luta é o monopólio da autoridade científica definida, de maneira inseparável, como capacidade técnica e poder social; ou se quisermos, o monopólio da competência científica (1976, p. 90).

De acordo com Bourdieu (1990), 'campo' representa um espaço simbólico, no qual diferentes atores lutam na determinação, validação e legitimidade de representações. Nesse sentido, no que se refere ao campo da educação em saúde no Brasil, várias áreas de conhecimento, hierarquia de campos, entre eles o político e econômico, e diferentes profissionais influíram na dimensão pedagógica da construção de um discurso hegemônico e normativo, caracterizando sua formação entre o final do século XIX e o início do século XX. Isso pode ser constatado na reconstituição histórica que faremos a seguir. ${ }^{3}$

Ainda, o artigo busca desenvolver uma análise sobre o diálogo entre os saberes dos profissionais de saúde e os saberes da população nas práticas educativas, tendo como referência a perspectiva de educação popular de Paulo Freire, que defendia como os saberes desses dois polos deveriam ser considerados com igual valor e legitimidade. Nessa perspectiva, propõe-se que a postura preconizada para a aplicação do método etnográfico no campo da Antropologia pode inspirar os educadores em saúde na articulação de saberes técnicos e populares para a compreensão e o enfrentamento dos problemas de saúde. 


\section{Educação em saúde no Brasil: a construção de um campo}

Enquanto na Europa do século XIX as discussões sobre saúde e educação cada vez mais se voltavam para os determinantes sociais, por meio das relações entre condições de vida e saúde-doença, prevalecia no Brasil no início do século XX uma perspectiva autoritária, formadora de normas e prescrições às quais os indivíduos deveriam se adequar, para a qual o modelo econômico do país teve grande influência. ${ }^{4}$ A construção dessa proposta de educação em saúde normativa, e mesmo coercitiva, deveu-se à afirmação do modelo agroexportador, que demandava a salubridade de portos e espaços públicos, como estruturante na economia do país.

Tomando-se como referência a cidade do Rio de Janeiro, então capital do país, pode-se dizer que as intervenções visando garantir a limpeza dos espaços públicos ocorreram, sobretudo, nos locais de moradia das classes pobres, que habitavam as regiões centrais das cidades, e nas zonas portuárias, por meio de uma série de ações, como a criação da polícia sanitária, a vacinação compulsória, a demolição de cortiços e a expulsão da população pobre para as regiões periféricas da cidade.

Conforme apontam Valla e Stotz (1994), as reformas urbanas e sanitárias empreendidas no início do século XX nas principais cidades do país emergiram da necessidade capitalista de disciplinar corpos e espaços, a fim de garantir a acumulação de condições favoráveis tanto para a produção e circulação de mercadorias quanto para a formação de um contingente de trabalhadores disciplinados e sadios. No entanto, a focalização no combate a algumas doenças, principalmente as transmissíveis e infecto-contagiosas, ainda era a tônica da grande maioria das ações de saúde, em detrimento de outros campos, como a saúde do trabalhador: “(...) combateu-se a febre amarela, principal causa de mortalidade dos trabalhadores imigrantes - o maior contingente da força de trabalho da indústria carioca - e deixou-se de lado qualquer cuidado com a saúde dos trabalhadores brasileiros" (Valla e Stotz, 1994, p. 20).

Isso evidencia que a saúde do cidadão em si e a melhoria da qualidade de vida em geral da população não eram o objetivo final das ações em saúde empreendidas, pois elas visavam ao estabelecimento de condições urbanísticas e higiênicas mínimas, que possibilitassem o desenvolvimento econômico do país.

Até 1920, a estrutura sanitária brasileira estava concentrada na resolução de problemas específicos. A ideia de prevenção e educação no que se refere a doenças que não tinham tratamento se fortaleceu, pois foram então introduzidas noções de higiene, imunizações e cuidados individuais cujo alvo principal era a criança. Para isso, vários médicos brasileiros, financiados 
pela Fundação Rockfeller, 5 foram formados em Saúde Pública na Johns Hopkins University. Por isso, o Movimento Sanitarista, que surgiu no Brasil após os anos 1920, recebeu forte influência da estrutura universitária norte-americana, com o intuito de reduzir ao máximo possível o poder coercitivo da polícia sanitária. Ainda assim, segundo Mascarenhas (1973), esse poder coercitivo adquiriu novamente força no governo Vargas, na forma de polícia sanitária. De acordo com Cardoso de Melo (1981):

A saúde e a educação vão ser políticas privilegiadas nas políticas sociais. A concretização dessas propostas (sanitária e escola-novista) vai depender da correlação de forças na disputa pelo poder político após a Revolução de 30 (...). As políticas sociais (de educação e saúde) vão ser formuladas em função do modo de inserção dos trabalhadores na produção (Cardoso de Melo, 1981, p. 34).

De acordo com o autor, a partir de 1942, os Estados Unidos formalizaram um acordo com o Brasil visando à exploração da borracha e minérios e ao aumento na produção de alimentos. Consequentemente, a atenção da saúde pública voltou-se para o homem do campo. Desse modo, novamente, médicos e cientistas sociais foram se especializar nos Estados Unidos em Health Education, para trazer novas metodologias e técnicas para as práticas de educação em saúde: educação de grupos e recursos audiovisuais com incentivo à participação dos indivíduos.

Novas áreas de conhecimento foram incorporadas à educação em saúde, com vistas à intervenção social, como o serviço social. Da mesma forma, à medida que a nova concepção preconizava uma educação sanitária que levasse em consideração os fatores sociais, econômicos e culturais que constituíssem 'barreiras' para as boas práticas de saúde, o conhecimento das ciências sociais passou a ser relevante. No entanto, apesar da inclusão desses domínios que valorizam outros fatores além dos biológicos na noção de saúde, essa ainda era percebida como uma responsabilidade individual.

A partir da década de 1950, dois movimentos se fizeram presentes: a imputação da responsabilidade individual, a consequente isenção da responsabilidade do Estado e a ausência de políticas públicas que interviessem nos condicionantes mais amplos de saúde da população, como a educação, o saneamento, a moradia etc. Com isso, as ações educativas em saúde ficaram restritas a programas e serviços destinados a populações à margem do jogo político central, e continuou-se a priorizar o combate às doenças infecciosas e parasitárias (Vasconcelos, 2001).

A partir da década de 1960, a educação em saúde no Brasil esteve basicamente subordinada aos interesses das elites políticas e econômicas, voltando-se para a imposição de normas e comportamentos considerados por elas adequados. Ganhou força a ideia da educação em saúde como forma de 
extinguir comportamentos de risco e de garantir a adoção de hábitos saudáveis (práticas higiênicas, vacinação, realização de exames etc.). Essa lógica reforçava a ideia de que o indivíduo é o maior responsável por sua saúde ou o maior culpado por sua doença; com isso, deixou-se de discutir até que ponto as soluções para problemas de saúde passam por ações socialmente sustentadas do ponto de vista cultural, econômico e político (Vasconcelos, 2001).

Paradoxalmente à repressão imposta pela ditadura militar em meados da década de 1960, houve o fortalecimento de uma série de experiências de educação em saúde que significaram uma verdadeira ruptura com o padrão que até então vinha se desenhando: o contexto de repressão e agudização das desigualdades fortaleceu os movimentos sociais e comunitários, que engendraram novas formas de resistências no campo da saúde (Smeke e Oliveira, 2001). Isso foi decorrência da insatisfação de muitos profissionais de saúde, intelectuais e acadêmicos com a política de saúde, que se voltava para a expansão dos serviços médicos privados, especialmente hospitais e policlínicas conveniados, nos quais as ações educativas não tinham espaço significativo. Esses profissionais, insatisfeitos com as práticas mercantilizadas e rotinizadas dos serviços de saúde, aproximaram-se da dinâmica de luta e resistência das classes populares, engajando-se no processo de formação de uma nova organização política da saúde, de forma que, no vazio do descaso do Estado com os problemas populares, configuraram-se iniciativas de busca de soluções técnicas construídas com base no diálogo entre o saber popular e o saber acadêmico (Vasconcelos, 2001).

A partir desse momento, uma série de iniciativas e movimentos surgiram e se fortaleceram, impulsionando a participação da população na discussão sobre saúde e condições de vida, como associações de moradores, o movimento operário, as experiências das Comunidades Eclesiais de Base (CEBs) etc. Nessa época também ocorreram as primeiras experiências de educação popular inspiradas na metodologia de alfabetização de adultos criada por Paulo Freire (2005). As propostas de conscientização crítica e libertadora no campo da educação também chegaram ao campo da saúde, cujas discussões passaram a se aproximar mais das realidades locais das populações. Para Freire, a valorização dos múltiplos saberes existentes, para além das fronteiras e delimitações do saber formal ou acadêmico, constitui um dos principais pilares da educação popular em saúde. Nesse sentido:

Um elemento fundamental do método da educação popular é o fato de tomar, como ponto de partida do processo pedagógico, o saber anterior do educando. No trabalho, na vida social e na luta pela sobrevivência e pela transformação da realidade, as pessoas vão adquirindo um entendimento sobre a sua inserção na sociedade e na natureza. Esse conhecimento fragmentado e pouco elaborado é a matéria-prima da educação popular (Brasil, 2007). 
Outro aspecto da educação popular bastante ressaltado por Freire (2005) e o qual se considera que a legitima como potente ferramenta de trabalho é o reconhecimento e a valorização das potencialidades das diversas populações, e não só de seus aspectos negativos.

Em 1967, a Faculdade de Saúde Pública da Universidade de São Paulo (USP) inaugurou o curso de Educação em Saúde Pública, para formar o educador em Saúde Pública, profissional preferentemente oriundo da graduação em Ciências Sociais. A introdução desse profissional no país encontrou barreiras para se difundir, devido ao regime autoritário vigente. De acordo com Cardoso de Melo, é o 'período negro' da educação sanitária onde a perspectiva de valorização do saber popular "Perde espaço para a nova racionalidade no interior do Sistema Nacional de Saúde (reflexo do período também negro para a sociedade civil, em particular para as camadas populares trabalhadoras)" (Cardoso de Melo, 1981, p. 39).

Nos anos 1970, os movimentos sociais ligados à saúde se fortaleceram e passaram a fomentar experiências de ações e serviços comunitários desvinculados do Estado e integrados a diferentes dinâmicas sociais locais. Com o início do processo de abertura política, que começou a ganhar força na segunda metade da década, movimentos populares que já tinham avançado na discussão das questões de saúde passaram a reivindicar novos serviços públicos e a exigir participação no controle de serviços e unidades de saúde existentes. Conforme Vasconcelos (2001), nessa época, a participação de profissionais de saúde nas experiências de educação popular trouxe para o setor uma verdadeira ruptura com a tradição autoritária e normatizadora que vigora até então em relação às classes populares.

Analisando as transformações na concepção de sujeito nos diferentes momentos históricos vivenciados no país, Smeke e Oliveira (2001) mostram como o surgimento de movimentos sociais e comunitários em um contexto de agudização das desigualdades sociais se relaciona com o esvaziamento de partidos e sindicatos, a omissão do Estado na garantia de direitos básicos e a noção de indivíduo que se assume como sujeito de direitos, como cidadão. Por outra parte, o discurso da educação em saúde passa a incorporar a noção de participação comunitária, com o intuito de aliviar as tensões sociais geradas pela deterioração das condições de vida da população, derivadas do modelo econômico vigente (Cardoso de Melo, 1981).

No decorrer da década de 1980, com a consolidação da abertura política no país e a criação do Sistema Único de Saúde (SUS), os movimentos surgidos nas décadas anteriores ampliam as suas reivindicações para mudanças mais globais nas políticas sociais; com isso, algumas das muitas experiências locais que eclodiram nas décadas anteriores perderam um pouco de seu protagonismo na luta por melhores condições de saúde, como é o caso das CEBs. No entanto, a experiência de integração vivida por intelectuais e líderes 
populares e o saber daí construído continuaram presentes, sendo inclusive levados para as instituições públicas, movimento que foi facilitado pela incorporação de militantes aos quadros políticos e profissionais de serviços e instituições governamentais.

Os anos 1990 foram marcados pelo avanço das ideologias neoliberais que, por meio de pressupostos como a diminuição da regulação do Estado na economia, a exacerbação da lei do livre mercado e a privatização de serviços estatais, representaram grande retrocesso nas políticas sociais e consequente aumento da desigualdade econômica e social. Esse movimento ocorreu em nível global e se acentuou no Brasil, a partir do governo Collor, situado entre 1990 e 1992. Nesse contexto, assistiu-se no país à expansão do chamado terceiro setor em áreas basais, como a educação e a saúde, principalmente mediante o fortalecimento das organizações não governamentais, as ONGs, entidades que se declaram de finalidade pública e sem fins lucrativos, e que passam a ocupar o vazio deixado pela ausência das políticas do Estado, realizando ações sociais com o financiamento do próprio Estado ou de entidades privadas.

O fortalecimento do terceiro setor é uma realidade até os dias atuais e impõe novos desafios à educação em saúde, dado que a lógica do cidadão como portador de direitos, que vinha se fortalecendo desde a década de 1970, resultou no esvaziamento do caráter reivindicatório das organizações populares e na desmobilização de movimentos sociais, que passaram a ser substituídos ou cooptados por relações de troca, como o clientelismo (Smeke e Oliveira, 2001).

Concomitantemente a isso, permanece o desafio de incorporar no cotidiano dos serviços e instituições de saúde a metodologia da educação popular e o protagonismo do cidadão. Nesse sentido, a educação popular passou a assumir papel mais amplo, conforme ressalta Vasconcelos: "na luta pela democratização do Estado, (...) o método da educação popular passa a ser um instrumento para a construção e ampliação da participação popular no gerenciamento e reorientação das políticas públicas" (Vasconcelos, 2001, p. 28).

Ainda na década de 1990, o movimento de organização de profissionais e educadores em saúde criou a Articulação Nacional de Educação Popular em Saúde (Aneps). Esse é um marco importante a ser destacado, pois indica que, apesar da conjuntura desfavorável, o período também foi marcado pela resistência de atores que acreditavam numa perspectiva de educação e saúde mais crítica, participativa e engajada.

\section{A contribuição da antropologia para uma educação em saúde dialógica}

No olhar para áreas faveladas ou comunidades de baixa renda, é comum que o etnocentrismo, ou seja, o julgamento de valor aplicado ao Outro tendo 
como parâmetro os próprios valores, prevaleça sendo enfocados quase sempre elementos como a pobreza, a violência e a escassez de forma geral. No entanto, esses espaços são territórios permeados de vida, em que estratégias de sobrevivência são elaboradas a todo o tempo e onde se usa a criatividade para lidar com a escassez de recursos. Além disso, dimensões como o prazer, a solidariedade e o lazer também estão muito presentes nesses lugares, embora dificilmente sejam reconhecidas por um olhar externo.

Nesse aspecto, muitas vezes os antropólogos são chamados para contribuir nas intervenções em saúde focadas nessas populações, assumindo o papel de mediadores para facilitar a compreensão da 'cultura' desse Outro. No entanto, é importante considerar que os próprios profissionais de saúde são igualmente portadores de uma 'cultura' e ethos profissional onde valores e ideologias estão presentes das práticas de educação sanitária. ${ }^{6}$

Segundo Vasconcelos, "grande parte das práticas de educação em saúde está voltada para a superação do fosso cultural existente entre as instituições de saúde e a população" (Vasconcelos, 2001, p. 29). Isso se dá por meio de experiências que, cada vez mais, reconhecem a diversidade e a heterogeneidade das classes populares. Mesmo que esse processo venha ocorrendo ainda de forma fragmentada, em experiências marcadas pela transitoriedade, já sinaliza a busca de novos padrões de enfrentamento dos problemas de saúde, caracterizados pela integração entre o saber técnico e o saber popular, pela via da mútua colaboração. Nesse sentido, a educação em saúde deixa de ser uma atividade mais realizada nos serviços, para ser algo que atinge e reorienta a diversidade das práticas ali realizadas (Vasconcelos, 2001).

Nesse aspecto, as noções de relativismo cultural introduzidas pelos estudos clássicos de Franz Boas (2004) coadunam-se com essa proposta. O relativismo cultural defende que cada cultura se expressa de forma diferente e deve ser interpretada no contexto dessa própria cultura, de maneira que não existe hierarquia de cultura ou saberes.

No âmbito da educação popular em saúde, Freire (1996) igualmente propõe a valorização dos saberes populares, ou saberes socialmente construídos na prática comunitária. Isso possibilita trazer uma perspectiva centrada no diálogo, na problematização e na ação comum entre profissionais e população. O autor ressalta que, no processo de educação popular, é importante trabalhar com base na premissa de que tanto os profissionais (ou educadores) quanto a população (educandos) sabem algo, mas também ignoram algo, e, portanto, todos sempre têm algo a aprender ou a ensinar por meio do diálogo e da troca de vivências.

Assim, o processo educativo passa a estar vinculado principalmente a elementos como a abertura, a disponibilidade e a curiosidade dos sujeitos de explorar novos saberes e conhecimentos. Essa perspectiva é também importante no sentido de afirmar a necessidade de horizontalização dos 
processos educativos, cuja consequência direta é o afastamento de posturas autoritárias ou messiânicas do educador, por vezes comuns no trabalho com segmentos populares, nas quais o profissional de saúde pode assumir o lugar de detentor do saber ou de portador de uma verdade salvadora.

Martínez-Hernáez (2010) igualmente tem uma perspectiva que vai ao encontro da proposta de Freire, defendendo um modelo dialógico de educação em saúde. Para o autor, esse modelo deve incluir três princípios: a multidimensionalidade, ou seja, as várias dimensões de risco ou dos fenômenos de morbi-mortalidade; a bidirecionalidade, que diz respeito ao intercâmbio de mensagens entre profissionais e os grupos sociais nos quais eles intervêm; e, finalmente, a simetria, que busca o estabelecimento da relação recíproca entre os atores sociais.

Segundo Martínez-Hernáez (2010), é nesse sentido que a postura do antropólogo, ao aplicar o método etnográfico cujo princípio é ir ao encontro de uma visão holística e contextualizada, pode servir de inspiração ao educador em saúde. O antropólogo busca um saber que é do Outro, despoja-se de seu jargão técnico e de seus valores para assimilar o vocabulário e o universo simbólico de seus informantes. Nesse sentido, preconizamos que o educador em saúde, ao assumir a mesma postura, contribui para maior simetria com corresponsabilidade e empoderamento dos atores e grupos sociais.

Da mesma forma, torna-se cada vez mais consensual a ideia de que as intervenções em saúde pública que ambicionam contar com a participação ativa das populações devem apoiar-se nos saberes e práticas locais (Neves, 2001). Para tanto, é necessário conhecer as construções simbólicas envolvidas nas representações dos indivíduos sobre saúde, educação, doença etc., considerando-se não só os condicionantes políticos e econômicos, mas também os condicionantes históricos e culturais que determinam os diferentes estados de saúde e doença. Essa proposta dialoga com a postura preconizada pela antropologia, que tem como pressuposto e método de investigação a aproximação (ou mesmo imersão) em determinado contexto sociocultural, como forma de conhecer seus códigos, suas crenças, suas relações de poder, seu modus operandi etc., forma de aproximação denominada método etnográfico.

O método etnográfico consolida-se como o principal método de investigação da antropologia, muito em decorrência das contribuições de Malinowski e de sua obra Argonautas do Pacífico Ocidental, publicada em 1922 e considerada até hoje uma das principais etnografias na história da antropologia. Na obra, Malinowski (1976) descreve algumas de suas experiências e observações referentes aos papua-melanésios que habitavam a costa e as ilhas da Nova Guiné, procurando enfatizar as questões metodológicas da pesquisa etnográfica e do desenvolvimento da técnica de observação participante, como a importância de ir a campo e ter contato direto com as populações pesquisadas, a necessidade de criação de condições adequadas 
para a pesquisa, a observação minuciosa do ambiente e da população pesquisados e a descrição detalhada da coleta, manipulação e registro de dados. Para Malinowski, mediante esses elementos, é possível descrever a constituição de determinada sociedade de maneira clara e nítida, assim como distinguir suas leis e regularidades.

As contribuições de Malinowski foram posteriormente discutidas e aprofundadas por diversos autores. Dentre eles, Clifford Geertz é um nome proeminente, ao ressaltar o caráter interpretativo do método etnográfico. Para Geertz (1989), a etnografia, mais do que uma questão de método ou de seleção de informantes, mapeamento de campos, elaboração de um diário etc., é uma descrição densa. O autor utiliza o conhecido exemplo dos garotos que piscam o olho por diferentes razões e motivações para apresentar a distinção entre descrição superficial e descrição densa. Na primeira, o etnógrafo procede a uma codificação em que sua investigação é vista como mera observação e descrição de códigos; na segunda, as situações produzidas são percebidas, interpretadas e descritas.

Nesse sentido, Geertz (1989) aponta que a descrição etnográfica tem três características fundamentais: ela é interpretativa; o que ela interpreta é o fluxo do discurso social; e a interpretação envolvida consiste em tentar salvar o 'dito' num tal discurso de sua possibilidade de extinguir-se, fixando-o em formas pesquisáveis. Uma quarta característica, ainda, seria o seu caráter microscópico, uma vez que o antropólogo aborda características sociais mais amplas, com base em um conhecimento extensivo de assuntos observados em um nível restrito/circunscrito. Por meio desses elementos, Geertz discute o papel do etnógrafo, afirmando que cabe a ele construir essa descrição densa, assim como buscar compreender a cultura de um povo, expondo sua normalidade, mas sem reduzir sua particularidade. $\mathrm{O}$ autor afirma ainda que:

O que o etnógrafo enfrenta de fato é uma multiplicidade de estruturas conceptuais complexas, muitas delas sobrepostas ou amarradas umas às outras, que são simultaneamente estranhas, irregulares e inexplícitas, e que ele tem que, de alguma forma, primeiro apreender e depois apresentar (Geertz, 1989, p. 20).

No entanto, Geertz ressalta que a interpretação do observador não pode ser o principal teste de validade de uma descrição cultural: ele lembra que todos os sistemas sociais têm um grau mínimo de coerência, senão não seriam sistemas. Assim, o papel do etnógrafo é 'inscrever' o discurso social, e essa inscrição deve buscar o significado do acontecimento de falar, não o acontecimento como acontecimento. Nisso consistiria a interpretação antropológica: traçar o curso do discurso social e fixá-lo numa forma pesquisável, como um discurso social elaborado (Geertz, 1989). Por meio dessa 'densi- 
dade' proposta por Geertz, constituída por uma interpretação apurada dos múltiplos discursos presentes nos níveis microscópicos das relações, seria possível adentrar um nível mais profundo dos saberes e representações de determinado contexto sociocultural.

Para James Clifford (2008), um importante teórico da antropologia contemporânea, a etnografia é um meio de produzir conhecimento a partir de intenso envolvimento intersubjetivo entre o pesquisador e seu campo de estudo. Utilizando uma analogia entre o método etnográfico e o cenário da escrita, Clifford fala da etnografia como uma tradução, e aponta que ela é uma forma de lidar com a complexidade decorrente das múltiplas subjetividades e dos constrangimentos políticos que estão presentes no campo de pesquisa e, muitas vezes, colocam-se acima do controle do etnógrafo. O reconhecimento do envolvimento intersubjetivo proposto por Clifford opõe-se aos ideais de neutralidade e isenção absoluta, que marcaram não apenas o discurso etnográfico clássico, mas também o próprio discurso científico. O reconhecimento de que há envolvimento subjetivo na pesquisa etnográfica (tanto partindo do investigador em direção ao campo quanto no sentido contrário) e que ele, em certa medida, é até mesmo necessário é abordado por autores como Velho (1979) e DaMatta (1978).

Lembrando do caráter interpretativo do trabalho antropológico enfatizado por Geertz, Velho (1979) afirma que o processo de conhecimento da vida social sempre abarca elementos de subjetividade e, por isso, é necessariamente aproximado e não definitivo:

a ideia de tentar pôr-se no lugar do outro e de captar vivências e experiências particulares exige um mergulho em profundidade difícil de ser precisado e delimitado em termos de tempo. Trata-se de problema complexo, pois envolve as questões de distância social e distância psicológica (Velho, 1978, p. 37).

O método etnográfico exige esse mergulho ao qual Velho se refere. É por meio da imersão que é possível ambicionar o acesso a distintas realidades sem o olhar estereotipado (ou mesmo preconceituoso) que permeia o senso comum. As distâncias que o autor bem ressalta vão muito além de fronteiras geográficas, mas facilmente se aplicam ao interior de uma mesma sociedade. Por exemplo, não é novidade que, em nossa sociedade, há diversos segmentos, dos quais muitos são marginalizados, o que se deve em grande parte às enormes desigualdades e contradições intrínsecas de nosso modo de organização social. De outra parte, Velho (1978) afirma que o fato de dois indivíduos pertencerem à mesma sociedade não significa que estejam mais próximos do que se fossem de sociedades diferentes. O que define essa proximidade é o fato de partilharem experiências comuns, que permitam determinado nível de interação. 
Assim, o fato de dispormos de um 'mapa' que nos familiariza com os cenários e situações sociais de nosso cotidiano, dando nome, lugar e posição aos indivíduos, não significa que conhecemos o ponto de vista e a visão de mundo dos diferentes atores em determinada situação social nem as regras que estão por trás dessas interações. Daí vem a importância do que DaMatta denomina de "transformar o exótico em familiar e o familiar em exótico" (DaMatta, 1978, p. 9), tarefa fundamental da etnografia, pela qual seria possível acessar as diferentes realidades existentes dentro de nossa sociedade. Dessa forma, a realidade (familiar ou exótica) sempre é filtrada por determinado ponto de vista do observador, ou seja, ela é percebida de maneira diferenciada. Para o autor:

Este movimento de relativizar as noções de distância e objetividade, se de um lado nos torna mais modestos quanto à construção do nosso conhecimento em geral, por outro lado permite-nos observar o familiar e estudá-lo sem paranoias sobre a impossibilidade de resultados imparciais, neutros (Velho, 1979, p. 43).

Já DaMatta (1978) aborda a questão do surgimento daquilo que pode ser demarcado como o elemento que se insinua na prática etnológica, mas que não estava sendo esperado, que ele denomina anthropological blues (em analogia com o ritmo musical blues, no qual a melodia ganha força mediante a repetição das frases). Os sentimentos e as emoções despertos no pesquisador seriam exemplos de alguns elementos não esperados ou 'hóspedes não desejados', decorrentes do envolvimento com o campo de pesquisa. Assim, o autor encara a etnografia como ferramenta de comutação e mediação, pela qual é possível construir pontes entre diferentes universos de significação.

Essa característica de mediação da etnografia revela-se fundamental no campo da educação em saúde que, como visto, muitas vezes se revela atravessado por discursos paralelos que não dialogam entre si. A postura preconizada pela antropologia na aplicação do método etnográfico pode inspirar profissionais de saúde na construção de uma educação em saúde mais dialógica.

\section{Considerações finais}

Geralmente os estudos antropológicos não têm objetivo de intervenção ou de aplicação. O projeto antropológico clássico, tal como preconizado por Malinowski (1976), consiste em ir a campo e coletar por meio da observação participante dados em um território geograficamente delimitado. Nas últimas décadas, no entanto, na América Latina e particularmente no Brasil, os 
antropólogos participam cada vez mais como mediadores nas intervenções com vistas à melhoria da saúde das populações minoritárias e de baixa renda. Os projetos de educação em saúde são exemplares nesse sentido. A principal contribuição da antropologia nesse contexto diz respeito ao diálogo com as equipes interventoras de forma a desestimular noções etnocêntricas e fornecendo como exemplo a postura do antropólogo etnógrafo em campo.

Como visto anteriormente, a educação em saúde é um campo multifacetado no qual convergem diversas concepções, tanto da educação quanto da saúde, que espelham diferentes compreensões do mundo e são demarcadas por distintas posições históricas, políticas, econômicas etc. sobre o homem e a sociedade. Nessa diversidade, grande parte das ações educativas em saúde tem sido marcada historicamente por um modelo autoritário e prescritivo. Como alternativa a esse modelo monológico, que embasa até hoje muitas das práticas educativas em saúde, as propostas de educação popular em saúde têm emergido nas últimas décadas como correntes contra-hegemônicas. A partir de uma leitura da realidade marcada pela densidade e pela mediação, como propõe o método etnográfico, e da busca do diálogo com diversos saberes advindos da educação popular, pode-se pensar na possibilidade de construção de uma educação em saúde pautada em critérios inversos àqueles que definem o modelo monológico.

Tendo em Paulo Freire um de seus principais referenciais, a educação popular propõe a valorização dos saberes populares - ou saberes socialmente construídos nas práticas comunitárias -, o que viabilizaria uma perspectiva centrada no diálogo, na problematização e na ação comum entre profissionais e população. Para Freire (2005), o processo educativo passa a se vincular principalmente a elementos como a abertura, a disponibilidade e a curiosidade dos sujeitos de explorar novos saberes e conhecimentos.

Nesse sentido, a postura do antropólogo, ao adotar o método etnográfico, pode inspirar o educador em saúde para alcançar um modelo de relação que seja mais dialógico, pois oferece uma base epistemológica e metodológica para estar entre os coletivos profissionais e populares. Pode-se afirmar ainda que a busca da alteridade é um dos elementos-chave que guiam o trabalho tanto do etnógrafo quanto do educador que trabalha na perspectiva popular, como aponta Geertz: "para entender as concepções alheias é necessário que deixemos de lado nossa concepção, e busquemos ver as experiências de outros com relação à sua própria concepção do "eu'" (Geertz, 2007, p. 91).

Dessa forma, como propõe Martínez-Hernáez (2010), o princípio da unidimensionalidade seria substituído pelo da bidirecionalidade, que consiste em um intercâmbio de mensagens, ideias, representações, informações entre os profissionais de saúde e os grupos populares, sem que esses últimos assumam o lugar de leigos ou ignorantes, mas passem a ser valorizados como produtores de múltiplos saberes, construídos a partir de seu arcabouço 
cultural, vivencial, histórico etc. Nessa perspectiva, também os profissionais deixam de ser vistos como meros reprodutores do discurso biomédico hegemônico, e passam a ser considerados atores de uma reconfiguração de sua experiência e de seu saber, baseada na proximidade com os saberes populares.

A unidirecionalidade daria lugar à referência multidimensional, que, por sua vez, estaria ligada a uma ampla análise da situação saúde-doença que tomasse como referência as relações de multicausalidade que estão por trás de condutas de risco ou dos fenômenos de morbi-mortalidade. A contribuição da visão antropológica, nesse caso, seria a preconização de uma visão holística e contextualizadora.

Já o princípio da hierarquia daria lugar ao da simetria, o qual propõe um modelo que coloque os diferentes atores sociais em posição de maior reciprocidade, sem desfigurar o papel ativo dos profissionais. O estabelecimento de um arranjo mais harmônico entre esses atores visa estabelecer também uma relação de corresponsabilidade entre ambos.

Por meio dessas reconfigurações, poder-se-ia almejar a formação de um modelo dialógico, no qual os múltiplos discursos envolvidos no entendimento e explicação da saúde, doença, cuidado etc. não somente convivem de forma orgânica, mas também se complementam, formando uma proposta de educação em saúde que considera os sujeitos como autores de suas trajetórias de saúde e doença.

Nesse sentido, o educador em saúde, usando as premissas recomendadas ao antropólogo na aplicação do método etnográfico, contribui para a melhor efetividade das intervenções, uma vez que essas premissas possibilitam uma articulação entre o saber científico e o popular. Assim, ele fornece uma base empírica para o desenho de investigações e projetos ligados à saúde, propiciando, ainda, a participação social nesse campo e a consequente diminuição da distância entre as propostas de educação em saúde e os múltiplos saberes da população.

\footnotetext{
Resumen El objetivo de este artículo es rescatar los aspectos relativos a la cosntitución de la educación para la salud como un campo científico. Muestra los principales cambios que han ocurrido desde las concepciones autoritarias y etnocéntricas en relación a sus grupos objetivo, hasta las propuestas actuales de educación popular de apreciación del saber popular, inspiradas en el pensamiento de Paulo Freire. Sostiene que la postura del antropólogo en el campo, al valorizar el saber del Otro, tan legítimo como el académico, puede ayudar a los profesionales de la salud en la práctica de una educación en la salud dialógica, para los grupos a los que se destina.

Palabras clave educación para la salud; antropología; salud colectiva; etnografía.
} 


\section{Notas}

1 Secretaria Municipal de Saúde do Rio de Janeiro, Rio de Janeiro, RJ, Brasil.

Mestre em Saúde Coletiva pela Universidade Federal do Rio de Janeiro.

$<$ joao_viniciusrj@yahoo.com.br>

Correspondência: Avenida Horácio Macedo, s/n, próximo à Prefeitura Universitária da UFRJ, Ilha do Fundão, CEP 21941-598, Cidade Universitária, Rio de Janeiro, RJ, Brasil.

2 Universidade Federal do Rio de Janeiro, Instituto de Saúde Coletiva, Rio de Janeiro, RJ, Brasil.

Doutora em Antropologia Social pela École des Hautes Études en Sciences Sociales, Paris, França. Pós-doutora em Antropologia da Saúde pela Escola Nacional de Saúde Pública Sergio Arouca, Fundação Oswaldo Cruz.

$<$ jaquetf@gmail.com>

3 O objetivo aqui é mostrar os diferentes interesses sanitários, políticos e econômicos, bem como os enfoques ideológicos que atuaram historicamente na constituição desse campo. Embora pertinente, não realizaremos aqui uma abordagem epistemológica da história das ciências. Nesse sentido, recomendamos a leitura de Georges Canguilhem (1970), que defende como a historicidade representa a efetuação de um projeto interiormente normatizado, mas atravessado por acidentes, retardado ou desviado por obstáculos, e interrompido por crises, quer dizer, momentos de julgamento e de verdade. Nessa perspectiva, o epistemólogo da ciência, Thomas Kuhn, igualmente privilegiava os aspectos históricos e sociológicos e psicológicos na análise da prática científica, ou seja, uma certa subjetividade e até mesmo 'irracionalidade' que acaba por ter um papel decisivo na imposição de determinadas teorias em detrimento de outras (Kuhn, 1992).

4 No entanto, no século XX a antropologia médica italiana, influenciada pelas ideias marxistas e sobretudo de Gramsci (1975), imprimiu à disciplina uma dimensão aplicada. Nesse sentido, destaca-se o nome de Tullio Seppilli, que desenvolveu atividades no Centro Sperimentale per l'Educazione Sanitaria, um centro cujas atividades permitiram que os antropólogos médicos contribuíssem para campanhas de informação sanitária, para a adaptação cultural das práticas clínicas e para a reforma dos serviços de saúde.

5 Sobre a importância da Fundação Rockefeller na formação da sociedade brasileira, ver Santos e Faria, 2003.

6 Essas ideias estão desenvolvidas em um exemplo prático, em pesquisa sobre as intervenções de uma organização humanitária francesa junto de populações vulneráveis africanas, em Ferreira, 2003. 


\section{Referências}

BARTOLI, Paolo. Antropología en la educación sanitaria. Arxiu D'Etnografia de Catalunya, Terragona, n. 7, p. 17-24, 1989.

BOAS, Franz. Antropologia cultural. Org. Celso Castro. Rio de Janeiro: Jorge Zahar, 2004.

BOURDIEU, Pierre. Le Champ scientifique. Actes de la Recherche en Sciences Sociales, Paris, n. 2-3, p. 88-104, jun. 1976.

BOURDIEU, Pierre. Coisas ditas. São Paulo: Brasiliense, 1990.

BRASIL. Ministério da Saúde, Secretaria de Gestão Estratégica e Participativa, Departamento de Apoio à Gestão Participativa. Caderno de educação popular e saúde. Brasília: Ministério da Saúde, 2007.

CANGUILHEM, Georges. Études d'histoire et de philosophie des sciences. Paris: Vrin, 1970.

CARDOSO DE MELO, Joaquim A. Educação sanitária: uma visão crítica. In: CANESQUI, Ana Maria; CAMARGO, Elizabeth S. P. de; BARROS, Maulisa Berti de. Educação e saúde. São Paulo: Cortez, 1981. p. 28-43.

CLIFFORD, James. Sobre a autoridade etnográfica. In: CLIFFORD, James. A experiência etnográfica. 2. ed. Rio de Janeiro: Editora UFRJ, 2008. p. 17-58.

DAMATTA, Roberto. O ofício do etnólogo, ou como ter 'anthropological blues'. In: NUNES, Edson de O. (Org.). A aventura sociológica. Rio de Janeiro: Zahar, 1978. p. 23-35.

FERREIRA, Jaqueline. Antropologia e clínica: o tratamento da diferença. Antropolítica, Niterói, n. 15, p. 121-135, 2003.

FREIRE, Paulo. Pedagogia da autonomia: saberes necessários à prática educativa. São Paulo: Paz e Terra, 1996.
FREIRE, Paulo. Pedagogia do oprimido. Rio de Janeiro: Paz e Terra, 2005.

GEERTZ, Clifford. Uma descrição densa: por uma teoria interpretativa da cultura. In: GEERTZ, Clifford. A interpretação das culturas. Rio de Janeiro: Guanabara Koogan, 1989. p. 13-41.

GEERTZ, Clifford. Do ponto de vista dos nativos: a natureza do entendimento antropológico. In: GEERTZ, Clifford. O saber local: novos ensaios em antropologia interpretativa. Petrópolis: Vozes, 2007. p. 85-107.

GRAMSCI, Antonio. Quaderni dal carcere. Torino: Einaudi, 1975. 4 v.

KUHN, Thomas. A estrutura das revoluções científicas. São Paulo: Perspectiva, 1992.

MALINOWSKI, Bronislaw. Argonautas do Pacífico Ocidental: um relato do empreendimento e da aventura dos nativos nos arquipélagos da Nova Guiné, Melanésia. São Paulo: Abril Cultural, 1976.

MARTÍNEZ-HERNÁEZ, Angel. Dialógica, etnografia e educação em saúde. Revista de Saúde Pública, São Paulo, v. 44, n. 3, p. 399-405, jun. 2010.

MASCARENHAS, Rodolfo S. História da saúde pública no estado de São Paulo. Revista de Saúde Pública, São Paulo, n. 7, p. 433-446, 1973.

NEVES, Teresa C. C. L. Representações sociais sobre dengue no modelo informacional das campanhas de saúde: abordagem sobre uma nova prática. In: CONGRESSO BRASILEIRO DE COMUNICAÇÃO, 24. Anais... Campo Grande: Intercom, 2001. Disponível em: <http://galaxy.intercom.org.br:8180/ dspace/bitstream/1904/4816/1/NP9NEVES. pdf>. Acesso em: 12 set. 2011. 
SANTOS, Luiz A. Castro; FARIA, Lina R. A Reforma Sanitária no Brasil: ecos da Primeira República. Bragança Paulista: Editora Universitária São Francisco, 2003.

SEPPILLI, Tullio. Il contributo dell'antropologia culturale all'educazione sanitaria. L'Educazione Sanitaria, Perugia, v. 4, n. 3-4, p. 325-340, 1959.

SMEKE, Elizabeth L. M.; OLIVEIRA, Nayara L. S. Educação em saúde e concepções de sujeito. In: VASCONCELOS, Eymard M. (org.). A saúde nas palavras e nos gestos: reflexões da rede educação popular e saúde. São Paulo: Hucitec, 2001. p. 115-136.
VALLA, Victor V.; STOTZ, Eduardo. Educação, saúde e cidadania. Petrópolis: Vozes, 1994.

VASCONCELOS, Eymard. M. Educação popular e a atenção à saúde da família. São Paulo: Hucitec, 2001.

VELHO, Gilberto. Observando o familiar. In: NUNES, Edson de O. (Org.). A aventura sociológica. Rio de Janeiro: Zahar, 1979. p. 123-133.

Recebido em 22/09/2011

Aprovado em 08/04/2014 
